\title{
LITERATURA NO ENSINO MÉDIO: CONTEÚDO E INSTRUMENTO DE ENSINO
}

\section{João Gomes da Silva Neto *}

Resumo: Este artigo propõe uma discussão sobre o lugar da literatura na aula de língua portuguesa no ensino médio. Dada a complexidade circunstancial em que está envolto o sistema educativo brasileiro, trata-se de questionamentos sobre uma problemática cujos componentes se mostram, a um só tempo, difíceis de entender (pesquisar) e de controlar: referimo-nos sobretudo aos problemas relativos à política educativa nacional (os programas de curso, os investimentos orçamentários, os objetivos), a formação dos professores e suas ações efetivas em classe, a circulação da imprensa especializada (literária, didática, pedagógica) e as limitações sócio-econômicas que atingem o professor, o aluno e o aparato escolar. No cruzamento desses problemas, encontram-se implicações teóricas e práticas relativas à obra literária, em face da didática e das imposições restritivas dos conteúdos e das avaliações escolares.

Palavras-chave: ensino médio; leitura; literatura; ensino/aprendizagem

Considerações preliminares

Abordar a presença da literatura na sala de aula implica refletir, entre outras coisas, sobre os usos que a escola faz do material literário que indica a seus alunos e, por esse intermédio, no âmbito mais específico do ensino médio, sobre as concepções de leitura e de literatura postas em prática no processo de didatização do fato literário. ${ }^{(*)}$ Essa problemática envolve, ainda, um questionamento sobre as relações que se estabelecem entre essa prática e as vivências efetivas

Doutor em Educação, professor do Programa de Pós-Graduação em Estudos da Linguagem da UFRN.

(*) Este trabalho é resultado de leituras preliminares feitas no âmbito do projeto de pesquisa $O$ material didático: literatura e letramento, que ora conduzimos. Centrado no ensino médio, esse projeto se interessa pela transposição didática da literatura, sob um enfoque dos estudos da linguagem. 
de leitura dos alunos, no mundo fora da escola. Para além do enfoque ostensivo de uma problemática já bem disseminada em pesquisas na área de educação, sobretudo no domínio da leitura, tem-se aqui mais propriamente uma discussão que levanta questionamentos para reflexão, que um repertório descritivo e constativo de investigações sobre o tema.

De fato, dada a complexidade circunstancial que envolve o atual sistema educativo brasileiro, propomos aqui alguns questionamentos sobre uma problemática cujos componentes se mostram difíceis de entender (pesquisar) e de controlar: referimo-nos sobretudo aos problemas concernentes à política educativa nacional (os programas de curso, os investimentos orçamentários, os objetivos), a formação dos professores e suas ações efetivas em classe, a circulação da imprensa especializada (literária, didática, pedagógica) e as limitações sócio-econômicas que atingem o professor, o aluno e o aparato escolar, quer público, quer privado. No cruzamento desses problemas, tem-se ainda a especificidade da obra literária, em face da didática e das implicações restritivas dos conteúdos e das avaliações escolares, no trato com o fenômeno artístico em si e com as experiências de leitura dos alunos.

Para situar o problema, podemos começar adotando uma postura teórico-crítica segundo a qual, no espaço escolar, a literatura se apresenta, de forma genérica, com um duplo estatuto: ela é, ao mesmo tempo, um modelo a ser imitado e instrumento para se produzir outros discursos, e também um objeto de estudo científico e de conhecimento (BIARD e DENIS, 1993, p.16). Logo de entrada, entendemos que os passos de uma abordagem desses temas inevitavelmente conduzem nossas especulações para a confluência de fatores complexos, que certamente demandam maior profundidade de apreciação. No entanto, uma apreciação da problemática, por breve que seja, torna-se necessária no âmbito de uma busca mais abrangente de compreensão dos modos como ocorre a aula de literatura, no atual
contexto do ensino médio.

\section{A literatura faz-se conteúdo e instrumento de ensino}

Em seus objetivos gerais, o ensino médio apresenta, na prática, a dupla função de terminalidade e de continuidade. Para uma determinada clientela, majoritária, ele tem funcionado como preparação para os concursos de ingresso ao ensino superior 
(concursos vestibulares); para uma outra, propõe um currículo que está voltado mais especificamente para o trabalho, através dos cursos técnicos profissionalizantes. Assim, em atenção aos objetivos mais imediatos do ensino médio, a literatura passa a ser mais propriamente sinônimo de conteúdo programático a ser ensinado e assimilado, e não de leitura a ser praticada, com fins em si mesma, enquanto atividade lúdica e estética.

Neste ponto, acreditamos que, nas circunstâncias atuais do ensino brasileiro, sobretudo no âmbito público, não é sem propósito um questionamento sobre o papel da literatura no ensino médio, nos moldes em que é abordada e utilizada em sala de aula. De qualquer modo, enquanto objeto estético com fim em si mesmo, o texto literário suscita mais problemas e restrições ainda. Quando apropriada pela instituição de ensino formal, a literatura pode assumir vários papéis e, com isso, tornar mais complexa a tarefa de compreensão das conseqüências decorrentes de sua presença na escola. ${ }^{1}$ Ora, enquanto modalidade artística da expressão cultural de um povo, a literatura sempre tem estado sujeita aos condicionamentos político-econômicos das sociedades em que circula. Daí, decorre que ela tem sido continuamente manipulada, quer em sua fatura, pelas coerções circunstanciais que envolvem o universo autoral, quer em sua recepção, também condicionada a coerções de natureza vária, sobretudo aquelas que direcionam o horizonte de expectativas do leitor ou delimitam e restringem o processo de leitura, conforme sua história de experiências pessoais com produtos culturais os mais diversos, inclusive a própria literatura.

1 No processo de didatização, a escola apropria-se de um produto cultural e torna-o conteúdo escolar (ou saber institucionalizado), objeto de ensino/aprendizagem e, portanto, de avaliação. As implicações são sérias, no que se refere à imprescindível manutenção da especificidade e integridade da literariedade do texto: pergunta-se, por exemplo, como é possível preservar o caráter de uso não utilitário da linguagem, como é próprio do texto literário? E ainda, como se dará o tratamento pedagógico de seu aparato discursivo, sobretudo no resgate de seus aspectos estéticos e lúdicos, em atividades que privilegiam sobretudo o plano conceitual da leitura? 
Literatura, história e função social

Alargando ainda um pouco o campo de questionamentos de nossas reflexões, podemos nos perguntar agora se há espaço para as artes, diante da vida prática, numa realidade social em que o ensino de nível médio é sobretudo utilitarista: prepara para os concursos vestibulares às universidades ou delimita a escolaridade máxima de um contingente de jovens que completa a força potencial de trabalho, a qual, a cada ano, vê-se renovada e acumulada. É nessa realidade que pensamos a presença das formas de arte de expressão escrita.

De fato, a arte literária se vê, pois, em seu consumo, submetida a condicionamentos socioculturais e econômicos, os quais, por sua vez, apontam para conotações políticas pertinentes - o que, aliás, ocorre com as demais formas de manifestação artístico-cultural no Brasil. Em tais circunstâncias, o texto (não só o literário) e o aluno são percebidos como elementos de um paradoxo instalado entre as fronteiras do contexto normatizante da escola e as vicissitudes do mundo ao seu redor. Nas circunstâncias atuais da educação brasileira, sobretudo no âmbito público, não é sem propósito, portanto, um questionamento sobre o papel da literatura no ensino médio, nos moldes em que tem sido abordada e utilizada em sala de aula. E afinal, nós nos interrogamos - e isso reflete perguntas correlatas, dirigidas freqüentemente aos professores: será que há lugar para a literatura num grupo de indivíduos que, em última instância, querem basicamente instrumentos para conseguir melhores empregos?

Para entendermos melhor esse estado de coisas, precisamos também de algumas informações sobre os percursos das práticas de leitura e da produção literária no Brasil, sempre de algum modo vinculadas aos modelos educacionais adotados ao longo de nossa história. Em linhas gerais - considerados os limites de aprofundamento deste artigo-, podemos perceber que a adoção da literatura como objeto de ensino tem seguido vários caminhos, mas todos em coerência com necessidades específicas dos projetos educacionais que se sucedem, do Brasil colonial aos dias de hoje. Em manuais, seletas e compêndios literários, podem ser identificadas diretrizes e procedimentos pedagógicos que bem revelam as diferentes filosofias da educação que os precedem e definem, diretrizes e procedimentos esses também coerentes com aqueles projetos. 
Para o momento, é bom lembrarmos que, em função das diferentes idéias existentes a respeito da educação, surgem também diferentes métodos de educação. Vale lembrar, ainda, que tais idéias estão vinculadas de modo indissociável aos vários aspectos da estrutura social, principalmente a língua, o sistema político, o potencial econômico e a religião. Nesse sentido, são notórias as distinções entre os perfis das escolas brasileiras dos jesuítas aos primórdios da República Velha, do Estado Novo às reformas educacionais pós-64. Estas últimas concernem particularmente à nossa discussão, tendo em vista as mudanças operadas então nos currículos das disciplinas ditas clássicas ou humanas, culminando com os encaminhamentos curriculares mais recentes, promovidos pela nova LDB (Lei ${ }^{\circ}$ 9.394).

De fato, diante dos planos governamentais que se sucederam imediatamente ao golpe de 64 , e que, na ocasião, atendiam a demandas político-econômicas de expansão, já não era suficiente a promoção do desenvolvimento do indivíduo em sua singularidade, abstraído de suas relações sociais. Menos que a formação humanista de seus contingentes, a escola, a partir de então, deveria concentrar parte significativa de seus esforços na formação de mão-de-obra qualificada, em função daquelas demandas. Ao abordar esse assunto, em seu texto A escolarização do leitor; a didática da destruição da leitura, Lilian Lopes Silva (1984, p.39) afirma que,

na verdade, a nova política educacional previa [...] apenas um adestramento que a aproximaria da qualificação exigida pelo setor industrial. Não podemos esquecer que a renovação do ensino fez parte de um projeto maior, de cunho político e econômico, fruto da revolução e do governo militar e que uma vez implantado ajudaria a consolidar o "milagre brasileiro" em todos os níveis.

Surge, portanto, nesse contexto, a necessidade de se equipar a população com habilidades socialmente necessárias, e os educadores passam a treinar pessoas para assumir determinados papéis na sociedade. Desse modo, a educação formal do ensino médio, assim pensada e executada, assume também a função de agente estratificante dos contingentes egressos: para uns tantos, tem-se no ensino médio o objetivo de terminalidade, para uns poucos, o de continuidade. 
No primeiro caso, para além daqueles que compõem o considerável grupo de evasão escolar (e que não atingiram, portanto, essa terminalidade, na sua formação básica), forma-se um contingente de sujeitos cujas competências correspondem a um mínimo de preparação para o trabalho, alguns com certa proficiência profissional e técnica (a ser eventualmente atualizada em cursos de qualificação e requalificação, posteriores). Estes, por diversas razões, logo entram na oferta do mercado de trabalho e, em consequiencia, encerram seus estudos formais; o outro contingente, relativamente bem mais restrito, é identificado como o conjunto daqueles cuja formação básica está voltada para o domínio dos conteúdos previstos nos exames vestibulares. Paralelamente, o caráter seletivo do acesso ao ensino superior dá margem ao surgimento e à ampliação dos conhecidos cursos de preparação ao vestibular. Aliás, como é notório, esse tipo de curso pretende minimizar as limitações ou lacunas de aprendizagem dos candidatos, em sua formação escolar; na prática, funciona como que um verdadeiro adendo ou extensão obrigatória e inevitável da Educação Básica. Nesse ponto, não é muito difícil entender que a literatura, aqui também, tende a ocupar um lugar particularmente problemático, enquanto objeto de ensinoaprendizagem.

Quanto aos rumos mais recentes que tem tomado a educação nacional, em seu papel na chamada "sociedade tecnológica" - e dispensando maiores considerações a respeito, uma análise mais detalhada dos novos parâmetros curriculares não aponta para mudanças substanciais nesse quadro. No entanto, ainda assim, vale uma observação: a esse propósito, mudando apenas as bases de sua retórica, em que desloca os interesses educacionais de um "paradigma" da "profissionalização" para um outro, o do "processo produtivo", a nova LDB, no seu Art. 35, institui para o ensino médio "a preparação básica para o trabalho e a cidadania do educando", e, para ser ainda mais coerente com esse educando, inserido na "esfera da produção", no seu Art. $36 \S 2^{\circ}$, a nova LDB também pressupõe que esse nível de ensino "poderá prepará-lo para o exercício de profissões técnicas” (Ver Brasil, 1999 a).

Neste ponto de nossa discussão, é preciso observar, também, que a formação de professores constitui um fator crucial, nessa problemática: as lacunas aí localizadas são, não apenas cada vez mais preocupantes, como também evidentes - resultado de um quadro 
complexo, cuja análise não tem lugar na presente discussão, mas que, no entanto, deve ser referido, sobretudo diante da constatação generalizada e imediata de que as novas diretrizes e bases da educação nacional não encontram, ainda, repercussão efetiva sequer nos programas de formação de docentes. Enquanto isso, percebe-se que a pesquisa na área de leitura já apresenta, entre nós, sinais de vitalidade e avanço, embora ainda incipiente, se consideradas a dimensão da problemática e as especificidades de nossa realidade de ensino/aprendizagem - e, nesse campo, a área de leitura de literatura é ainda mais restrita. Considere-se, como mais um complicador do quadro, que o produto dessa pesquisa ainda não se mostra evidente na formação dos docentes, sob a forma de propostas de trabalho adequadas e de encaminhamentos à reflexão sobre sua atividade em sala de aula.

\section{Texto didático, crítica e teoria literárias}

A partir de procedimentos pedagógicos adotados na utilização da literatura, tanto pelo professor quanto pelo texto didático, podemos fazer um levantamento da linha evolutiva ${ }^{2}$ das disciplinas de referência envolvidas nas análises de textos literários, ao longo da história da crítica literária, que vai da hermenêutica e teologia à mais recente crítica acadêmica. Isso revela, de certo modo, o que há por trás das tarefas propostas aos alunos, que normalmente se compõem de exercícios de compreensão de texto e de redação.

Para melhor esclarecer esses modos como os estudos literários concebem a literariedade de um texto e, com isso, alargarmos nossa visão sobre as implicações decorrentes no trato com a literatura na escola, é interessante revermos brevemente as duas principais abordagens da leitura, com as quais se alinham as teorias da literatura (cf. EAGLETON, 1983, 1994; JAUS et al., 1979; JAUS, 1996). Em suas feições gerais, estas teorias estão associadas às duas correntes teóricas da leitura mais aceitas e difundidas: uma dessas correntes, dita interna, apóia-se na idéia de que o texto possui uma estrutura

2 Cf.:Brandão, Micheletti (1997), Chiappini (1993, 1997), Lajolo (1984), Lajolo, Zilberman (1996), Molina (1984), Pondé et al. (1984), Perez (1991), Silva (1984, 1997), Vieira (1989, 1992) e Zilberman (1984, 1991). 
intrínseca que condiciona e determina as atividades do leitor - são as teorias centradas no texto; a outra corrente, dita externa, pensa a leitura a partir das condições definidoras do contexto da recepção, isto é, das influências da situação de leitura sobre o receptor - são as teorias contextuais, centradas no leitor. Aliás, é oportuno frisar que, no cotidiano escolar, tende-se a privilegiar atividades de leitura identificadas com uma didática voltada para concepções internas e imanentistas do texto.

De fato, através de procedimentos pedagógicos centrados na natureza intrínseca do texto, muitas vezes pede-se ao aluno o sentido "real" de uma determinada obra (ou fragmento), numa reação típica diante do suposto hermetismo dos códigos discursivos da literatura; em outras ocasiões, solicita-se a observação e apreciação da oratória e persuasão. Como na retórica antiga $^{3}$, procura-se, com isso, desenvolver uma pedagogia que melhore o desempenho na expressão oral e escrita, através da análise de técnicas usadas por grandes autores; ao serem investigados os estilos, os efeitos, as figuras e as implicações éticas das obras literárias, estão sendo retomados os procedimentos da poética clássica, fundada no épico e no drama; as análises meticulosas, envolvendo a morfologia, o léxico e a semântica, em articulações com a gênese autoral, trazem procedimentos das críticas textual e genética para os manuais escolares; alguns desses, mais recentes, já propõem atividades de reconstituição, adaptação e mudança de gênero do texto literário, como reflexos da crítica revisionista e profissional que, em termos gerais, tem como princípio a intervenção no trabalho criativo do autor e, conseqüentemente, uma certa influência na feitura final da obra literária contemporânea.

Além disso, deve-se lembrar que, em suas orientações ou roteiros de leitura, o livro didático também pode revelar conotações sociais oriundas da crítica marxista. O direcionamento pedagógico será, nesse caso, concebido levando-se em conta aspectos extrínsecos ou externos do texto literário. Essa modalidade da crítica baseia-se fundamentalmente nos conceitos dialéticos de base (ou infraestrutura)

3 Na retórica antiga a produção do discurso previa no mínimo três fases: a elocução, a disposição e a invenção. Encontramos aí pontos de contato com os cursos de redação baseados em esquemas temáticos e tipológicos de texto. 
e superestrutura, e suas conexões com o conceito de ideologia. Este último, por sinal, já se encontra largamente utilizado como instrumento operatório em análises textuais, as quais preconizam a idéia de que o texto é um produto cultural por excelência. Em suas acepções mais genéricas, e naquilo que se aplica à análise textual, esse conceito tem se prestado a promover a inserção histórica do texto literário. Nesse sentido, enquanto artefato ideológico, o texto tenderia a incorporar certas categorias conceptuais da ideologia. A interpretação crítica estaria, então, apoiada na idéia de que a ideologia reflete a base econômica dos produtos culturais (reflete porque se deriva desta mesma base) e, ao mesmo tempo, promove a hegemonia de um modo particular de ver o mundo. Analisado por essa modalidade crítica, o texto literário adquire conotações políticas particularmente agudas que se situam ao nível da transcendência do texto, ou seja, tais constatações fundam-se nos fatores circunstanciais que envolvem sua produção e recepção literárias, tendendo-se, além disso, a atribuir-lhe um caráter de "instrumento" de ação social.

Num campo mais restrito, mas não menos importante, age também a crítica acadêmica, que desenvolve uma versão profissional da análise literária, voltada para professores e alunos. Dessas duas últimas posturas críticas derivam os procedimentos pedagógicos baseados na estilística e no estruturalismo, ambos fundamentados, por sua vez, nas lingüísticas geral e aplicada; mais recentemente, nas propostas de trabalho de leitura direcionadas para os estudos da linguagem, constatam-se influências da análise do discurso, da sociolingüística e da pragmática. Em decorrência, tem-se maneiras diversas de entender o texto literário, nas práticas da sala de aula : ora ele é como parte da língua, e portanto passível de uma descrição gramatical por analogia (estruturalistas), ora ele é parte da língua, podendo ser analisado em suas várias instâncias de uso e atualização. Infere-se daí, também, a relativa complexidade que envolve a didatização da literatura e sua conseqüente inserção no processo de ensino/aprendizagem.

Neste ínterim, deve-se frisar que, bem mais recentemente e de forma ainda um tanto difusa, começa já a despontar, em uns poucos 
manuais de língua portuguesa (ou de estudos de texto) ${ }^{4}$, a adoção de tendências de uma crítica voltada para a estética da recepção e para as teorias do efeito literário. Na prática, isso se traduz sobretudo na escolha mais adequada e criteriosa dos textos reproduzidos e nas propostas de atividades que os acompanham, de mais a mais preocupadas com o incentivo e a sensibilização à leitura. ${ }^{5}$ Dessa forma, para além de encaminhamentos metodológicos voltados para o estudo de linguagem, esses manuais também apresentam propostas de trabalho voltadas para o incentivo à leitura, através do desenvolvimento do gosto pelas manifestações escritas da arte. Isso ocorre como reflexo direto da adoção de algumas concepções de leitura identificadas com o resgate dos componentes estético, lúdico e afetivo dos textos literários.

\section{Didatização da literatura e livro didático}

No caso particular do Brasil, a literatura que aqui circula entre os alunos é aquela veiculada basicamente no âmbito da escola, através de amostragens inseridas nos livros didáticos de língua portuguesa e de literatura brasileira, ou em reproduções de textos distribuídos em folhas avulsas, durante a aula, ou, ainda, de forma assistemática, através de títulos indicados pelos professores, geralmente orientados por critérios historiográficos ou de estilos de época, e nem sempre pelas experiências de leitura dos próprios professores. Esse material didático é o que atende à expressão genérica de texto literário, conforme apropriada pelos discursos didático e pedagógico, nas várias

4 Baseamo-nos na observação empírica de diversos manuais do ensino fundamental e do ensino médio, no contexto da pesquisa anteriormente citada, assim como ao longo dos trabalhos concernentes à disciplina Metodologia do ensino da leitura, que ministramos regularmente no Curso de Letras da UFRN. Essa observação também se estende ao acompanhamento das bibliografias adotadas pelos autores desses manuais: elas pressupõem a adoção de certas posturas críticas e metodológicas, como vimos discutindo até então.

5 Retomando a questão envolvendo as políticas educacionais e a leitura, há pouco comentadas, fazemos menção especial aos trabalhos desenvolvidos pelo Proler - Programa Nacional de Incentivo à Leitura e, em particular, neste âmbito, pela Fundação Biblioteca Nacional (cf. BRASIL, 1998a, 1998b). 
atividades escolares pertinentes (falando-se em termos de material didático escrito, note-se que texto literário não se confunde com texto didático; englobando o primeiro, este caracteriza-se pelos discursos conceitual, explicativo e diretivo, próprios dos conteúdos escolares e dos procedimentos e encaminhamentos pedagógicos).

Aqui, aliás, é importante frisar que a natureza dos textos circulados em classe depende essencialmente das escolhas e procedimentos pedagógicos do professor, em atendimento às diretrizes curriculares e às circunstâncias próprias de sua realidade de trabalho. Conforme dados de uma pesquisa intitulada A circulação de textos na escola (Silva et al., 1997, p. 32), baseada em aulas de Língua Portuguesa, esse processo de didatização dos textos ocorre em dois níveis:

O primeiro nível de didatização é o encontrado no livro didático : o autor do manual seleciona os textos que, no geral, não foram escritos visando ao ensino e elabora um trabalho sobre eles. Assim, o professor, ao adotar o livro, ou ao consultá-lo, estará lançando mão de textos já didatizados, sendo apenas um transmissor do processo de didatização do material que leva a seus alunos.

O segundo nível é aquele em que o educador pode instituir-se como sujeito do processo, pesquisando textos em diversas fontes e trazendo-os para a sala de aula, com a sua proposta de trabalho.

Observe-se que esse processo de didatização do texto (literário ou não) está condicionado à noção de pretexto, ou seja, ele se dá em função da proposta de trabalho do professor ${ }^{6}$. Isto significa dizer que o texto normalmente se presta para atividades que nem sempre objetivam o desenvolvimento das habilidades de leitura - o que não exclui, de qualquer modo, uma certa atividade de leitura, embora considerada um tanto restrita.

Neste ponto da discussão, acreditamos que não é difícil fazermos uma transposição dessas constatações para o quadro específico da aula de literatura, considerando-se o grande número de

6 Como bem ilustram as sugestões de trabalho em Geraldi (1997, p. 88103). 
textos literários usados na aula de língua portuguesa e a evidente afinidade dos percursos teóricos e metodológicos desses áois tipos de aula, desde as primeiras séries do ensino fundamental. Embora isso não constitua um problema que lhe seja específico, o que se deve ressaltar, no caso desse tipo de texto, é que o seu processo de didatização nem sempre ocorre segundo critérios e abordagens adequados. Os estudos que se têm feito nessa área são unânimes quando apontam a existência de problemas de adequação desses textos, tanto no que se refere aos conteúdos das aulas, quanto aos padrões de interesses e expectativas do público leitor a que se destinam. Pelo que se tem observado, os textos didáticos de literatura se apresentam, via de regra, mutilados e descontextualizados.

A escolha textual e seus determinantes

No que concerne ao material literário encontrado nos livros didáticos e nos textos reproduzidos na escola, é preciso lembrar que a natureza, a dimensão e a funcionalidade da amostragem podem ser definidas, a priori, por quatro instâncias ideológicas, não hierarquizadas, mas intimamente relacionadas entre si: pelo lado de sua elaboração, temos primeiramente a tradição da crítica e da historiografia literárias, que faz a inserção de certos autores e obras nas coletâneas clássicas, de acordo com os cânones estéticos que definem a literariedade desses textos; numa segunda instância, tem-se o autor do livro didático, a quem compete deliberar sobre a amostragem textual ali presente, conforme seus objetivos educacionais mais específicos e segurdo seus critérios pessoais de suficiência e adequação, dentro ainda dos limites e diretrizes que o mercado
editorial lhe confere.

Pelo lado que se volta para seus usuários, temos na instituição escolar uma terceira instância definidora do perfil do livro didático. De fato, a escola continuamente seleciona e redefine o material de leitura destinado a seus contingentes, na medida em que tende a ver no livro didático um recurso pedagógico suficiente e prático para o cumprimento de suas metas educacionais - veja-se que essa seleção submete o material de leitura a critérios de progressão de habilidades e conteúdos, próprios ao ensino seriado (tais considerações se aplicam tanto para os livros remetidos às escolas públicas, quanto aos adotados pelas escolas privadas). 
Movimento contínuo, isso faz com que o autor do livro didático atenda a tais critérios, ajustando sua produção à demanda escolar. Aliás, implicitamente endossado pela escola, em atenção aos objetivos dos programas de curso, esse ajuste pode ser entendido também como representativo dos critérios gerais que os estabelecimentos de ensino adotam na escolha das leituras que destinam a seu público. Para Geraldi (1997), há vários critérios de seleção de leitura na escola, entre os quais ele aponta dois, bastante significativos. Um deles diz respeito ao fato de que os professores costumam fazer suas escolhas dentro do universo autoral de seu conhecimento, através da leitura da obra ou de alguma indicação que lhe parece segura. ${ }^{7}$ À primeira vista, esse critério parece óbvio e sem maiores motivos de questionamento, mas, se visto por outro ângulo e num foco mais próximo de nossa realidade profissional do cotidiano, encontramos ainda outras implicações, da parte dos professores. Nesse sentido, Geraldi (op. cit., p.85) afirma que,

Como esses profissionais, de modo geral, estão há anos impedidos de ler, por falta de tempo, incentivo, dinheiro, etc., a sua seleção vai se pautar pelos autores com quem tiveram a chance de conviver um dia, no passado. [...] Autores com os quais se habituaram por força da sua formação, da tradição, da profissão e da imposição e que para eles não significam risco algum.

Em outras palavras, pode-se afirmar que o material pedagógico utilizado no encaminhamento dos trabalhos em classe também é selecionado em função da história de vida do professor, no tocante a suas experiências efetivas de leitura. Quer ele tenha ou não consciência disso, ele traz consigo modelos de aprendizagem que são moldados pela sua história pessoal e social, seus valores de referência e sua relação com a instituição (Biard e Denis, 1993:9). No outro lado do problema, em que se encontram os alunos, a situação dos critérios de seleção de suas leituras não é muito diferente: os fatores pragmáticos de sua existência escolar e familiar também são, portanto, definidores de suas vivências com a leitura. Esta se faz não apenas na experiência proporcionada pelo livro didático - que já é, por si só,

Trabalhos específicos sobre esse aspecto podem ser encontrados em Marinho (1998). 
positiva nesse sentido, mas com quaisquer outras leituras, no contato diário desses alunos com as várias modalidades de registros e suportes que o seu mundo lhes oferece. $\mathrm{Na}$ base desses fatores, que na atual conjuntura socioeconômica brasileira se apresentam mais restritivos que facilitadores, percebe-se que estão, como forças motoras da formação do jovem leitor, a situação econômica do seu meio social e as histórias de leitura das pessoas com quem convive.

Ainda com relação aos critérios de seleção de leitura na escola, apontados por Geraldi (op.cit., p.86), um outro direcionamento vem de concepções educacionais emprestadas da Psicologia, e se apóia na adoção "de critérios de adequabilidade, interesse e motivação para a leitura", conforme a faixa etária e a série dos alunos. Como se a escola pudesse também "seriar e graduar os problemas, as realidades, as fantasias e a leitura dos alunos", encontramos, nesses critérios, um duplo argumento que justifica sua adoção: há um argumento científico, que julga o livro adequado à criança, e um outro pedagógico, que o torna adequado ao programa da matéria. Na opinião desse autor, uma restrição a esses critérios é que não há, geralmente, por parte dos professores, maiores questionamentos sobre a propriedade didática e até mesmo conceitual de suas escolhas, quando da seleção das leituras destinadas aos seus alunos. Quanto ao livro didático, por sua vez, acreditamos que a sua escolha e sua adoção trazem implícita, quase sempre, uma aceitação irrestrita da autoridade do seu autor: afinal - é possível que assim se presuma -, esse tipo de livro deve ter sido escrito por alguém que sabe mais que seus
usuários, professores e alunos.

Assim, e sem pretender com isso esgotar o assunto, encontramos no professor uma quarta instância definidora do perfil do livro didático, no que diz respeito à amostragem do material literário ali encontrado. Na medida em que o emprega, quase sempre sem restrições, como um instrumento mediador de suas ações pedagógicas,
esse profissional torna efetivo e, de certo modo, finaliza o direcionamento qualitativo e quantitativo agenciado pelas instâncias que o precedem - a escola, o autor do livro didático, a crítica e a historiografia literárias. No entanto, muito freqüentemente, diante dos desafios e do imprevisível das situações de aula, o livro didático acaba por tolher a iniciativa e o discurso do professor, na preparação e execução de suas atividades pedagógicas: por várias razões, este quase sempre se vê compelido a utilizar tal recurso sem maiores restrições; 
de fato, o professor nem sempre extrapola seu campo de ação em busca de outras fontes de material para subsidiar o seu trabalho: o livro didático preenche e delimita seu horizonte de atuação.

Enquanto isso, uma vez tomado como um produto acabado de verdade e suficiência, o texto didático pode funcionar como um elemento de interposição entre o professor e seus alunos, interferindo em suas escolhas e tentativas de superar suas próprias limitações ou, ainda, na exploração de seu potencial inventivo e criador. Lembremos que, via de regra, constam dos manuais de língua portuguesa e de literatura, as listas de exercícios sobre vocabulário, os roteiros de leitura e os questionários de "compreensão". As aulas tendem, desse modo, a ser organizadas em função das modalidades de leitura que esses dispositivos estratégicos vêm a produzir (Cf. Silva Neto, 1999).

Problemas de adequação: literatura e contexto de leitura

Uma vez introduzido no livro didático, o texto literário - este aqui entendido como fragmento exemplar da obra de um certo autor recortado nas proporções adequadas ao ensino da língua materna e da historiografia literária, enquanto é, ao mesmo tempo, enquadrado na moldura redutora do texto didático. ${ }^{8}$ Entenda-se aqui, nessa moldura, mais um fator que tende a minimizar as oportunidades de contato do aluno com obras literárias. Aliás, problemas e contradições que se constatam nas vivências de alunos e professores com o texto literário podem também ser pensados em função de um contexto mais amplo, que se volta para além do espaço escolar e é extensivo aos demais tipos de texto, sobretudo aqueles divulgados na forma de livros. Pesquisas sobre o assunto revelam que

Essas constatações têm estado na pauta de preocupações de pesquisas nas áreas de leitura, produção de texto, ensino/aprendizagem de línguas e literatura. Dessas pesquisas, têm surgido encaminhamentos no sentido de que se reverta esse quadro redutor, no trato com a leitura. São exemplos desses trabalhos: Brandão (2003), Brandão e Micheletti (1997), Chiappini (1993, 1997), Chiappini, Geraldi, Citelli (1997), Citelli, A. (2000), Citelli, B. (2003), Geraldi (1996, 1997), Kleiman (1998), Micheletti (2002), Lajolo (1982, 1984, 1993), Magnani (1989), Malard (1995), Moita Lopes (1996), Souza (2001) e Zilbermann, Bordini (1989). 
a leitura de livros diminui de acordo com a maior vivência na escola, ou seja, os educandos das séries iniciais lêem mais que os das séries finais. Essa tendência é esperada levando-se em conta que, à medida que avançam na escolarização, o material que a eles se destina e a sua forma de abordagem não são adequadamente preparados. [...] Essa falta de motivação pela leitura está diretamente ligada ao processo de descontextualização que sofrem os textos no livro didático (SILVA et al., 1997, p.64-65).

Um resultado prático e imediato dessa descontextualização é que, mesmo na escola, lê-se pouco e de modo fragmentado. Por outro lado, numa extensão do problema, fora da escola, a leitura de literatura praticamente inexiste. Aliás, em seu cotidiano, o aluno se vê geralmente num contexto praticamente alheio à leitura de qualquer espécie, sobretudo de literatura. A escola experimenta, desse modo, um impasse em seus propósitos: procura estimular e promover habilidades e atitudes de inegávei valor no desenvolvimento integral da criança e do jovem, como é o caso da leitura e da apreciação do texto literário, mas encontra dificuldades em precisar o alcance prático e efetivo de tais propósitos, na vida prática dos contingentes egressos
da educação formal.

Por outro lado, em função dos modos pelos quais a escola se apropria da literatura como objeto de educação, no que diz respeito à disciplina língua portuguesa, os objetivos das tarefas de leitura se confundem com os previstos nos programas de curso referentes à literatura. Em função da diversidade de tais objetivos, é necessário que se estabeleça uma distinção entre o tipo de leitura de que tratamos aqui e aquela normalmente praticada no ensino fundamental, como
veremos mais adiante.

\section{A leitura na escola e outras leituras}

Nas classes do ensino fundamental, os livros didáticos adotados costumam dispor os textos de modo gradual, seguidos das respectivas tarefas de leitura e escrita, numa progressão crescente no que se refere à extensão e relativa complexidade do conjunto de seus enunciados, sobretudo nos níveis formal e temático, de modo a coincidirem - textos e progressão didático-pedagógica - com os objetivos do ensino seriado nessa área do conhecimento. Com isso, 
pretende-se dar à criança um acesso gradual à sistematização da língua e ao registro escrito, de modo que, em seus aspectos de suficiência e adequação, o material literário ali presente se preste para tais fins. De fato, nesse primeiro nível, o "trabalho com a língua tem como finalidade a formação de leitores competentes e, consequëntemente, a formação de escritores", de maneira que os alunos sejam capazes de "valorizar a leitura como fonte de informação, via de acesso aos mundos criados pela literatura e possibilidade de fruição estética, sendo capazes de recorrer aos materiais escritos em função de diferentes objetivos" (BRASIL, 1997, p.42). Levado assim para a escola, o texto literário não é objeto de experiência lúdica, com fins em si mesmo, como é próprio desse tipo de um artefato artístico; ao contrário, ele é aí, tão-somente, um instrumento de ensino/aprendizagem.

Já no ensino médio, o material literário e o teórico sobre literatura estão organizados num conjunto de conteúdos, metodologias e formas de avaliação tais que, ao fim desse período, o educando demonstre "conhecimento das formas contemporâneas de linguagem" (LDB, Art. 36, $\S 1^{\circ}$ ), sem perder-se de vista que essa etapa do Ensino Básico tem, entre outras, como finalidade, "a preparação básica para o trabalho e a cidadania do educando como pessoa humana, incluindo a formação ética e o desenvolvimento da autonomia intelectual e do pensamento crítico" (Art. 35). Ora, entendida em sua complexidade, a literatura, assim como as Artes em geral, entra na escola de ensino médio "como expressão criadora e geradora de significação de uma linguagem e do uso que se faz dos seus elementos e de suas regras em outras linguagens" (BRASIL, 1999a, p.41). Por sua vez, "O estudo da gramática passa a ser uma estratégia para compreensão/interpretação/produção de textos e a literatura integra-se à área de leitura" (BRASIL, 1999b, p.38). Espera-se, portanto, do aprendiz, o desenvolvimento de competências e habilidades que o levem à compreensão do fenômeno literário no duplo enfoque da interdisciplinaridade e da contextualização, o que deve resultar no desenvolvimento de seu espírito crítico, tomado no conjunto das competências básicas necessárias ao exercício da cidadania e ao desempenho de atividades profissionais. O que significa dizer que, aqui também, a literatura é mais uma vez tomada como instrumento de ensino/aprendizagem e, quanto a isso, o próprio texto dos PCN não se furta a um encaminhamento pedagógico dessa natureza, quando nos apresenta afirmações do tipo: "A literatura é um bom exemplo do 
simbólico verbalizado." (id., p.41), "O texto literário se apropria desse jogo do possível com maestria. A propaganda faz o mesmo." (id., p. 43). Uma vez integrada "à área de leitura", a literatura é tomada como um texto a mais a ser compreendido/ interpretado/produzido, como é o caso do texto da propaganda, ali apontado a título de exemplo.

Como já havíamos lembrado, no ensino médio, além de instrumento, a literatura também assume a forma de conteúdo escolar. Entretanto, não é despropósito lembrar que, nas práticas pedagógicas do cotidiano atual, a literatura que se apresenta nesse nível de ensino tende a permanecer aquela pautada na historiografia, segundo os critérios das escolas literárias e dos estilos de época, presentes na maioria dos manuais escolares. Além disso, a tomar como referência os avanços mínimos nos programas dos cursos de Letras, no que se refere aos avanços teóricos e metodológicos no trato com a leitura e com a literatura em sala de aula, as limitações na formação dos professores vão adiar ainda por um certo tempo o projeto de educação da nova LDB.

Vale salientar que tais distinções didático-pedagógicas nos dois níveis de ensino estão também associadas à natureza do texto literário empregado. No ensino fundamental, os textos, em sua maioria, são colhidos da literatura infanto-juvenil, cuja produção em nosso contexto é fortemente condicionada pelos objetivos e pela progressão desse currículo. No nível seguinte, por sua vez, utilizam-se textos que ilustram a literatura consagrada pela história e pela crítica literárias. Neste caso, a produção dos textos literários não está, certamente, condicionada a certos níveis de escolaridade ou variações nas habilidades de leitura dos seus receptores. Tais textos são produzidos, a priori, em função de um leitor virtual, de proficiência plena - e nem sempre identificado, como já vimos discutindo, com o aluno do currículo de ensino médio. Vista nesta perspectiva, a crise de leitura de literatura se projeta, portanto, em suas causas, para além do âmbito escolar e se deixa transparecer também, no cotidiano do aluno e nas suas experiências de vida. Note-se, além disso, que o problema não está restrito ao âmbito do literário: na verdade, pode-se falar em termos de uma crise de leitura que se estende às várias modalidades de apresentação da expressão escrita da linguagem. 
Leitura em crise: para além dos limites da escola

De fato, pesquisas recentes sobre o assunto constatam que as raízes dessa crise têm ligações com a escola e a família. Entre outras coisas, afirma-se que, por várias razões, o aluno não tem acesso ao texto literário e à sua leitura integral, quer no lar, quer na escola, enquanto que o professor, por sua vez, não preenche essas lacunas. Em regra geral, o aluno não usa a biblioteca da escola ou da comunidade - quando esta existe e/ou lhe é disponível, enquanto que, ao mesmo tempo, o texto literário costuma apresentar-se mutilado e descaracterizado pelo livro didático e pelas folhas avulsas em que é reproduzido na escola. ${ }^{9}$

Desse modo, em virtude da falta de acesso efetivo por parte do aprendiz e de encaminhamentos pedagógicos adequados na sala de aula, o texto literário parece não ter muito significado para a vida prática fora da escola; além do mais, esse tipo de texto é quase sempre entendido, por parte do aluno, como elemento gerador de mais uma obrigação escolar. Tem-se aqui um agravante no fato de que, no âmbito escolar, a promoção da leitura tende a ocorrer sempre via paradigmas voltados para a literatura, com toda a carga de valores afetivos e culturais que, por seu intermédio, costuma-se atribuir ao livro, enquanto índice de prestígio e supremacia da língua escrita, com as inúmeras implicações de poder social e político decorrentes, dentro e fora da instituição escolar. Veja-se que isto ocorre numa situação em que - um outro agravante - o aluno não costuma ver esse tipo de leitura sendo praticada em seu lar, nem tem acesso a outras formas de expressão cultural que o ajudem na apreciação do texto literário. Ao mesmo tempo, tem-se observado que essa perda de sentido pela leitura de obras literárias ocorre, de forma progressiva e cada vez mais nítida,

9 Sobre as informações concernentes aos quatro aspectos da problemática da leitura e do ensino de Literatura, aqui apresentados, nós nos reportamos sobretudo aos trabalhos encontrados em Brandão, Micheletti (1997), Chiappini (1993), Lima (1996), Rocco (1981), Silva et al. (1997), Zilberman (1991a) e Zilberman, Bordini (1989). Aliás, deixe-se bem claro que essa crise não pode ser imputada a problema exclusivo da realidade brasileira. Afora as especificidades próprias da história de formação do nosso leitor, os traços gerais da crise não se afastam do que se verifica junto aos jovens, nas escolas e fora delas, em países de escolarização notoriamente elevada (Cf. Dufays, Gemenne, Ledur, 1996) 
na medida em que o aluno se aproxima do ensino médio. Esse fato está, certamente, relacionado com as concepções que escola e professor têm de leitura e de texto literário, consideradas as implicações pedagógicas que refletem tais concepções. Acresce, ainda, como fator interveniente nessa problemática, o fato de os professores não estarem adequadamente preparados para lidar com atividades envolvendo o texto literário, ou em que este constitui objeto
específico de aula.

Uma dessas implicações diz respeito às lacunas culturais que, no cotidiano da sala de aula, escavam um fosso entre a realidade prática do aluno e o mundo projetado pela escola, através das vivências de leitura a que o submete, em suas atividades de promoção do material escrito. Esse distanciamento toma corpo sobretudo por efeito de concepções de ensino e de leitura que tendem a relegar em segundo plano as próprias vivências do aluno e, em consequiência, negam-lhe a oportunidade de fazer da leitura, promovida pela escola, um contínuo de suas experiências de vida, traduzidas em e por outras leituras (do texto escrito às múltiplas visões de mundo, através das
também múltiplas modalidades de veículos intercos presentes no cotidiano brasileiro atual). Cortam-se, pois, dessaticativos os vínculos possíveis entre as vivências de leitura literária e as várias formas de leitura que se praticam na vida ordinária e profissional, dentro da família, nas ruas, na comunidade. De fato, como nos lembra Maria Helena Martins (1994, p.167),

Uma visão abrangente e realista de práticas culturais não institucionalizadas pode favorecer a percepção de quanto e como essas práticas estão interessando e ensinando os jovens brasileiros, à revelia da própria escola. E esta continua a menosprezar linguagens não verbais ou a ignorar textos não preconizados por ela ou ainda a utilizar-se de umas e outros apenas como recursos
aliciadores, sem de fato valorizá-los.

Assim, vamos percebendo que a tão lamentada carência de leitores está ligada a preconceitos letrados. Enfatizase a ausência de leitura e deixa-se de considerar o que de
fato é lido e como isso é feito.

Olhando uma outra faceta da questão que envolve as práticas de leitura promovidas pela escola, voltadas basicamente para o livro didático, e esse descompasso com as experiências efetivas de leitura 
dos alunos, nós nos reportamos às palavras de Eliana Yunes (1997, p.9), para quem,

Trabalhar a promoção da leitura, inevitavelmente, passa pela formação do leitor, com uma pedagogia e uma teoria renovadas à luz da interdisciplinaridade e do resgate do homem, indivíduo, cidadão que precisa sentirse sujeito histórico para interagir no ato de ler. E não apenas de livros, mas de imagens e outras linguagens com o repertório de sua vivência e com o acervo cultural que lhe sustenta uma visão do mundo.

Numa transposição imediata do que foi dito para a situação de aula de leitura, em qualquer que seja a disciplina, fica claro que a formação escolar do jovem leitor passa também pela dimensão cultural em que este se vê inserido. Ora, no caso mais específico da literatura, se a atividade escolar não consegue estabelecer e efetivar liames duradouros e significativos entre o texto a ser lido e o contexto sociocultural e lingüístico a que pertence o aluno leitor, este certamente não se identifica com a obra, não encontra ali os vínculos mínimos necessários que a situem no quadro de uma realidade como a sua própria, ou que lhe seja plausível e próxima - mesmo que imaginária. Como se pode notar, tendo-se em conta ainda o que temos discutido até aqui, a efetividade desse reconhecimento entre leitor e texto tem vínculos diretos com o trabalho do professor e com os critérios de adoção do livro didático - em outras palavras, com o uso que a escola faz da literatura.

Livro didático e indicações de leitura

Infelizmente, em sua especificidade e função no cotidiano da sala de aula, o livro didático de literatura também não tem preenchido as lacunas de vivências de leitura do aluno; assim como o professor que o adota, esse instrumento didático nem sempre promove um estímulo para que o aprendiz desenvolva uma atitude positiva para com a leitura de um modo geral. Ao contrário, para o aluno, no cotidiano de sua vida escolar e familiar, o livro didático nada mais significa que a expressão material da leitura-tarefa promovida pelo professor, em função de objetivos do currículo seriado que ambos têm que cumprir - objetivos, aliás, nem sempre muito claros para o estudante. 
Essa mesma impressão negativa sobre as vivências de leitura é transposta, guardadas as proporções das experiências de cada um, para as obras literárias indicadas ao aluno. O efeito imediato desse estado de coisas é, certamente, um desinteresse generalizado pelos livros, mesmo em suas formas mais difundidas e sugestivas. O que se segue é o desestímulo para outras leituras e, em conseqüência, a destruição gradativa do gosto pela leitura eventualmente adquirido ao longo das séries do ensino fundamental. Esse estado de coisas se agrava quando se considera que o aluno do ensino médio, via de regra, tem acesso à literatura apenas por intermédio do livro didático e do material copiado que é distribuído em sala. Tal fato constitui mais um fator negativo nos resultados práticos da escola, mais especificamente em seu papel na formação de leitores de e para o mundo. Justamente pensando nessa problemática, Perez (1991, p.87) argumenta que, com base no livro didático, e não na experiência da leitura do texto integral, o ensino de literatura

constitui um aglomerado amorfo de nomes e obras e um receituário inútil de conceitos teóricos. Dessa forma o ensino torna-se perverso, já que ele nega [...] a capacidade da literatura de confirmar a humanidade do homem. É preciso que o ensino de literatura na escola aponte para a concreta particularidade de nossa vida social.

De qualquer modo, nas práticas de sala de aula que se observam mais amiúde, a leitura é voltada menos para uma compreensão global que para a retenção de modelos de expressão escrita. Aqui, mais uma vez, há convergências nas informações colhidas em pesquisas pertinentes.

A redação também vai de par com a leitura escolar

Numa extensão das atividades em torno da leitura, o texto literário se presta indistintamente também como material e pretexto para promover a aquisição e aprimoramento do registro escrito. E este é um outro aspecto da problemática da presença da literatura na escola. Apoiada em práticas pedagógicas voltadas para a redação, a escola encara muitas vezes a leitura de literatura não como uma atividade com um fim em si mesmo, com objetivos próprios, mas como um meio de promover o acesso à norma culta da língua, 
geralmente através da literatura. Essa norma se traduz no padrão da escola, materializado na prática da redação que deve reproduzir, de certo modo, os valores e atitudes previstos pelos padrões normativos da língua.

Enquanto modalidade discursiva normatizada, a redação pode, em certas circunstâncias, funcionar também como uma expressão discursiva de visões de mundo também submetidas à norma e, portanto, parciais, enviesadas e redutoras da realidade, uma vez que torna efetiva uma modalidade de leitura (ou releitura) particularizada e dirigida do mundo. A leitura, orientada apenas para tais fins, bem como a redação que se lhe segue, pode gerar uma expectativa unilateral e passiva do mundo, produzindo um leitor acrítico e superficial. Como resultado imediato, os componentes artísticos e lúdicos da experiência com a leitura de literatura são seriamente minimizadas, senão completamente obliterados - aliás, há de se convir, tais componentes não se prestam aos processos tradicionais de didatização e avaliação escolar; não se deixam reduzir e explicar apenas na forma de um conhecimento sobre algo, i. e., de um conteúdo escolar, a ser ensinado e aprendido. Na leitura literária, o estético e o lúdico só são abstraídos enquanto efeitos das experiências imediatas com o texto, e implicam envolvimentos afetivos e emocionais de diversa ordem, dificilmente recuperáveis de forma objetiva no trabalho escrito - o que, aliás, já não é tão fácil através do trabalho com a expressão oral. Nos modos como costuma ser conduzida, a leitura associada à redação não consegue fazer com que o aluno intensifique e amplie suas experiências subjetivas com esse tipo de texto, nem tampouco que exprima de modo adequado seu estado de espírito, em consonância com aquilo que eventualmente lhe é suscitado pela poesia e pela ficção literária.

Isso não significa, no entanto, que essa experiência da redação, embora quase sempre limitada, não seja proveitosa, de algum modo, sobretudo na aula em que se pretende estudar também a língua portuguesa. Não precisamos fazer muito esforço para encontrar algumas razões que levam os professores de português a utilizar o texto literário como mais uma opção, entre os outros tipos de texto que frequientemente adotam em classe. Uma razão pode estar no valor do material autêntico - em exclusão aos exemplos de textos "fabricados", tão comuns nos livros didáticos de língua; uma outra pode estar também nos resultados traduzidos em forma de 
enriquecimento cultural e lingüístico do aluno: diante da literatura, mesmo numa tarefa voltada para a escrita, ele pode, de algum modo, usufruir os efeitos de seu envolvimento pessoal com a leitura, através do acesso a outros padrões de valores e visões de mundo, enquanto possibilidades de acesso ao sistema inventivo e ao imaginário da ficção. No entanto, como já foi falado anteriormente, o emprego desse recurso textual nem sempre atinge resultados satisfatórios na aprendizagem.

\section{Considerações finais}

Com vimos até aqui, os fatores que intervêm na apropriação do texto literário pela escola são vários e de difícil controle, e não ocorre de modo diferente no ensino médio. Enquanto campo de pesquisa, essa temática suscita muitas perguntas que ainda precisam ser respondidas ou, pelo menos, aprofundadas. Aliás, muito do que se tem feito em pesquisas nessa área ainda não está presente nos cursos de formação e qualificação dos professores de língua portuguesa, nem tampouco na sua prática em sala de aula. Esses profissionais ainda carecem de encaminhamentos de trabalho mais adequados à especificidade da obra literária, sobretudo diante do que preceituam os objetivos e as metas dos PCN na área de língua portuguesa, relativamente à linguagem e às práticas de leitura e escrita. Compondo essa problemática, considere-se ainda o que se preceitua para o ensino médio, no que se refere à literatura, como parte integrante daquela
disciplina.

De fato, a presença da literatura na escola implica a um só tempo a concorrência de fatores os mais diversos, quais sejam as políticas educacionais, os programas curriculares e as circunstâncias sócio-econômicas que envolvem e constituem o espaço escolar; a pedagogia do professor e suas limitações de formação, diante da especificidade dos textos e da natureza das tarefas associadas à leitura de literatura; e, além disso, a origem social do aluno, traduzida em sua história de vida, com suas restrições de leitura e seu conhecimento acumulado, em associação com as atitudes imprevisíveis e diferenciadas de cada um, quando de sua experiência com um fato artístico-cultural dessa natureza. Em certa medida, essa complexidade torna-se explícita no cotidiano de sala de aula, quer nos investimentos humanos e materiais exigidos pelas atividades que envolvem a leitura 
de literatura, quer na configuração discursiva resultante e ao mesmo tempo constitutiva das interações entre professor e alunos: durante as tarefas de ensino/aprendizagem, a manipulação conjunta de conceitos e categorias sobre literatura se confunde com a própria prática de leitura; uma vez que o ensino dessa disciplina se dá necessariamente com a leitura e se confunde também com o ensino da língua materna, a cena de aula se apresenta, então, como uma sucessão de atividades bastante complexas, em particular no tocante às interações discursivas que ali se produzem.

Referências

BIARD, J., DENIS, F. Didactique du texte littéraire. Paris: Nathan, 1993.

BRANDÃO, H. N., MICHELETTI, G. (Coords.). Aprender a ensinar com textos didáticos e paradidáticos. São Paulo: Cortez, 1997. (Aprender e Ensinar com Textos, 2).

BRANDÃO, H. N. (Coord.). Gêneros do discurso na escola: mito, conto, cordel, discurso político, divulgação científica. 4.ed. São Paulo: Cortez, 2003. (Aprender e Ensinar com Textos, 5).

BRASIL. Ministério da Educação. Secretaria de Educação Fundamental. Parâmetros curriculares nacionais: língua portuguesa. Brasília: Ministério da Educação/Secretaria de Educação Fundamental, 1997.

BRASIL. Ministério da Educação. Secretaria de Educação Fundamental. Projeto Pró-leitura na formação do professor. Brasília: MEC/SEF, 1998a.

BRASIL. Ministério da Cultura. Fundação Biblioteca Nacional. Proler: concepção, diretrizes e ações. Rio de Janeiro: MEC/FNDE/Casa da Leitura, 1998b.

BRASIL. Ministério da Educação. Secretaria de Educação Média e Tecnológica. Parâmetros curriculares nacionais: ensino médio; bases legais. Brasília: Ministério da Educação/Secretaria da Educação Média e Tecnológica, 1999a. 
BRASIL. Ministério da Educação. Secretaria de Educação Média e Tecnológica. Parâmetros curriculares nacionais: ensino médio; linguagens, códigos e suas tecnologias. Brasília: Ministério da Educação/Secretaria da Educação Média e Tecnológica, 1999b.

CHIAPPINI, L. Invasão da catedral: leitura e ensino em debate. Porto Alegre: Mercado Aberto, 1993.

CHIAPPINI, L, GERALDI, J. W., CITELLI, B. (Coords.). Aprender a ensinar com textos de alunos. São Paulo: Cortez, 1997. (Aprender e Ensinar com Textos, 1).

CHIAPPINI, L. Gramática e literatura: desencontros e esperanças. In: GERALDI, J. W. (Org.). O texto na sala de aula. São Paulo: Ática, 1997. (Na Sala de Aula). 17-25.

CITELLI, A. (Coord.). Outras linguagens na escola: publicidade, cinema e TV, rádio, jogos, informática. São Paulo: Cortez, 2000. (Aprender e Ensinar com Textos, 6).

CITELLI, B. Produção e leitura de textos no ensino fundamental: poemas, narrativas, argumentação. 3.ed. São Paulo: Cortez, 2003. (Aprender e Ensinar com Textos, 7).

DUFAYS, J.-L., GEMENNE, L., LEDUR, D. Pour une lecture littéraire: approches historique et théorique; propositions pour la classe de français. Bruxelas: De Boeck \& Larcier, 1996.

EAGLETON, T. Teoria da literatura: uma introdução. São Paulo: Martins Fontes, 1983.

EAGLETON, T. Critique et théorie littéraires. Paris: P.U.F., 1994.

GERALDI, J. W. Linguagem e ensino: exercícios de militância e divulgação. Campinas: Mercado Aberto, 1996. 1997. (Na Sala de Aula).

JAUSS, H. R. et al. A literatura e o leitor: textos de estética da recepção. (Sel., trad. e intr. Luís Costa Lima). Rio de Janeiro: Paz e Terra, 1979.

JAUSS, H. R. Pour une esthétique de la réception. Paris: Gallimard, 1996. (Tel, 169)

KLEIMAN, A. Leitura: ensino e pesquisa. Campinas: Pontes, 1989. 
LAJOLO, M. Usos e abusos da literatura na escola. Rio de Janeiro: Globo, 1982.

LAJOLO, M. Poesia: uma frágil vítima de manuais escolares. In: Leitura: teoria \& prática. Porto Alegre: Mercado Aberto, 1984.

LAJOLO, M. Do mundo da leitura para a leitura do mundo. São Paulo: Ática, 1993.

LAJOLO, M., ZILBERMAN, R. A formação da leitura no Brasil. São Paulo: Ática, 1996.

LIMA, A. Políticas educacionais e ensino de literatura brasileira. Recife: Editora Universitária da UFPE, 1996.

MAGNANI, M. R. M. Leitura, literatura e escola. São Paulo: Martins Fontes, 1989. (Texto e Linguagem).

MALARD, L. Ensino de literatura no $2^{\circ}$ grau: problemas e perspectivas. Porto Alegre: Mercado Aberto, 1995.

MARINHO, M. S., SILVA, C. S. R. Leituras do professor. Campinas: Mercado de Letras; Associação de Leitura do Brasil - ALB, 1998. (Leituras no Brasil).

MARTINS, M. H. O que é leitura. São Paulo: Brasiliense, 1994.

MICHELETTI, G. (Coord.). Leitura e construção do real: o lugar da poesia e da ficção. 3.ed. São Paulo: Cortez, 2002. (Aprender e Ensinar com Textos, 4).

MOITA LOPES, L. P. Oficina de lingüística aplicada; a natureza social e educacional dos processos de ensino/aprendizagem de línguas. São Paulo: Mercado de Letras, 1996.

MOLINA, O. O livro didático e as habilidades de estudo. In: Leitura; teoria \& prática. Porto Alegre: Mercado Aberto, 1984.

PEREZ, J. R. R. Lição de português: tradição e modernidade no livro escolar. São Paulo: Cortez, 1991.

PONDÉ, G. et al. O livro didático na área de comunicação e expressão: algumas idéias. In: Leitura; teoria \& prática. Porto Alegre, 1984.

ROCCO, M. T. F. Literatura/ensino: uma problemática. São Paulo: Ática, 1981. 
RÖSSING, T. M. K. Ler na Escola: para ensinar literatura no $1^{\circ}, 2^{\circ} \mathrm{e}$ $3^{\circ}$ graus. Porto Alegre: Mercado Aberto, 1988.

SILVA, A. C. et al. A leitura do texto didático e didatizado. In: BRANDÃO, H. N. e MICHELETTI, G. (Coords.). Aprender a ensinar com textos didáticos e paradidáticos . São Paulo: Cortez, 1997. (Aprender e Ensinar com Textos, 2). 31-93.

SILVA, L. L. M. A escolarização do leitor : a didática da destruição da leitura. In: Leitura; teoria \& prática. Porto Alegre, 1984.

SILVA, L. L. M. Às vezes ela mandava ler dois ou três livros por ano. In: GERALDI, J. W. (Org.). O texto na sala de aula. São Paulo: Ática, 1997. (Na Sala de Aula).82-87.

SILVA NETO, J. G. O discurso na aula de leitura e literatura no ensino médio: procedimentos e estratégias de explicação (tese de doutorado). Natal: UFRN, nov 1999.

VIEIRA, A. O prazer do texto: perspectivas para o ensino de literatura. São Paulo: EPU, 1989.

VIEIRA, A. Ensino de literatura e vestibular. In: Revista da Faculdade de Educação. Porto alegre, 18, 195-204, jul./dez. 1992.

YUNES, E. Prefácio. In: AMARILHA, M. Estão mortas as fadas?. Petrópolis: Vozes; Natal:EDUFRN, 1997.

ZILBERMANN, R., BORDINI, M. da G. (Coord.) . Guia de leitura para alunos de $1^{\circ}$ e $2^{\circ}$ graus. São Paulo: Cortez, 1989.

ZILBERMANN, R. A leitura e o ensino da literatura. São Paulo: Contexto, 1991. 